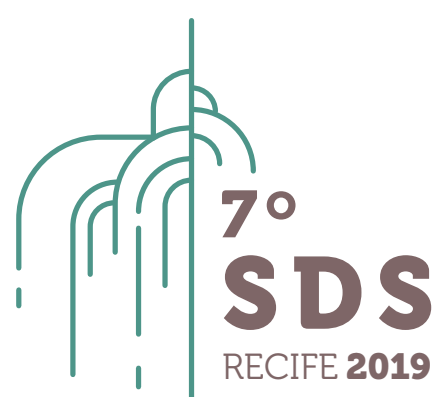

SIMPÓSIO SUSTAINABLE

DESIGN

\title{
Humanidade 2012: Do Impermanente ao Efêmero, um Protótipo de Solução Sustentável
}

\author{
Suzane Queiroz, Mestre em Design ${ }^{1}$ Alfredo Jefferson Doutor ${ }^{2}$ \\ ${ }^{1}$ PucRio, Departamento de Artes \& Design, sznarz@gmail.com \\ ${ }^{2}$ PucRio, Departamento de Artes \& Design, afferson@puc-rio.br
}

Resumo. A proposta deste artigo é aprofundar o conhecimento acerca da experiência de criação e realização do pavilhão Humanidade 2012. Será relacionado o potencial de redução do impacto ambiental na construção de uma arquitetura impermanente criativa, conceitual e significativa. O método de construção adotado, que inseriu a arquitetura impermanente do pavilhão em um sistema construtivo pré e pós existente a ele, conduz a necessidade de uma classificação mais precisa de tal arquitetura não somente como impermanente, mas sim como efêmera, palavra ressignificada a partir do resgate etimológico de seu sentido como aquilo que dura pouco, mas que tende a reaparecer ciclicamente, tendendo ao infinito. Contextualizado no Rio+20, o último encontro global voltado para a sustentabilidade, o Humanidade 2012 reúne características e resultados suficientes para que seja possível considerá-lo, de acordo com Ézio Manzini, um protótipo de solução sustentável rumo a um rompimento sistêmico com o objetivo de alavancar a criação de propostas de projetos efêmeros criativos, reorientados para a redução do impacto ambiental.

Palavras-chave. arquitetura, efêmero, impermanente, impacto ambiental sistema, sustentabilidade. 


\section{Introdução}

As questões ambientais são sem dúvida de ordem global, mas tal escala, por ser humanamente inalcançável, se constitui paralisante. Individualmente as pessoas tendem a se sentir impotentes diante da magnitude dos problemas do mundo natural. "A novidade exige pensar, agir e viver frente ao mundo", escreve Michel Serres (2009/2017, p.96). Nesse momento de transição, não se pode perder de vista um importante recurso que é a ação local resultante da mudança de hábitos individuais e coletivos nos âmbitos pessoal, familiar, social e profissional de cada ser em sua respectiva cadeia de atividades. As questões ambientais podem e devem ser tratadas também localmente. Pequenas ações quantitativas resultam qualitativamente, e podem em conjunto atingir grandes proporções. Trata-se de uma questão de escala de alcance que reverberará a partir da atuação de cada indivíduo ou grupos de indivíduos. A escala local torna palpável e viável a atuação individual, encorajando a participação e o engajamento das pessoas nas mudanças de suas realidades rumo à diminuição do impacto global das atividades humanas. Essa percepção é articulada por John Thackara em seu livro plano B, no qual ele enfatiza a importância de aproximar conceitos da economia, como proximidade e localidade da busca de transformações:

\footnotetext{
... em um contexto de sistemas complexos e mudanças constantes, mesmo pequenas ações podem ter um poderoso e transformador efeito no cenário mais amplo. [...] Pensar local e pensar pequeno não é uma abordagem de horizontes estreitos e não é uma abdicação de responsabilidades em prol do cenário mais amplo. Pelo contrário, passaremos do presente ao futuro em uma série de passos pequenos, mas cuidadosamente considerados. A proximidade e a localidade são características naturais da economia. (THACKARA, 2008, p. 126)
}

Importante evidenciar que identificar limites constitui a delineação de novos contornos para novas possibilidades e novas ideias. Isso se aplica ao tema da sustentabilidade no campo das construções arquitetônicas impermanentes, diante dos limites do planeta,. Para tanto será aprofundado o conhecimento acerca do projeto e da realização do pavilhão Humanidade 2012, que foi um equipamento arquitetônico construído para funcionar durante o período da Conferência das Nações Unidas sobre Desenvolvimento Natural (CNUDN). Mais conhecida como Rio+20, a conferência global foi realizada na cidade do Rio de Janeiro em 2012. O Pavilhão Humanidade 2012 teve curadoria da diretora artística Bia Lessa e concepção arquitetônica da arquiteta Carla Juaçaba. À convite de Lessa, Juaçaba se imbuiu no desenvolvimento de um projeto arquitetônico o qual apresentasse a mensagem de sustentabilidade intrinsecamente, não constituindo somente um invólucro estético funcional para abrigo do tema. A intenção de Lessa se alinha com a afirmação de Pallasmaa: "a arquitetura dirige, proporciona e emoldura ações, percepções e pensamentos." (2017, p.96).

No Pavilhão Humanidade 2012 observa-se a imbricação criativa e sustentável no desenvolvimento do projeto de arquitetura. Delineia-se então que o objetivo deste artigo é relacionar a concepção criativa associada ao bem-estar e prazer estético na fruição do público com o potencial de redução do impacto ambiental do sistema construtivo adotado no projeto humanidade 2012. Testemunhou-se nesse projeto a colocação em prática do que Ézio Manzini vai chamar de protótipo de solução sustentável rumo ao que ele estabelece como rompimentos sistêmicos fundamentais e necessários nesse momento de transição de atitude da humanidade perante aos materiais e a natureza (2008).

Através do sistema de andaimes, a construção a partir de peças modulares, se insere em um sistema maior que a própria construção e transcende a duração da ideia do projeto. Um 
sistema que já existia antes da sua realização e que continuará existindo após a sua desmontagem. Em uma realidade onde materiais duram mais do que ideias, o designer Rafael Cardoso propõe no campo do design o que é passível de aplicação na atividade criativa de concepção e realização de arquiteturas impermanentes:

O princípio da reversibilidade tange igualmente soluções muito simples e tradicionais ao design, como o uso de módulos. Todo sistema modular prevê múltiplas possibilidades de uso e, portanto, gera um potencial para estender a sobrevida do artefato apenas pelo rearranjo de suas partes em novas combinações... (CARDOSO, 2016, p. 164)

Arquitetura impermanente ou arquitetura efêmera? Essas entre outras foram algumas das classificações do pavilhão Humanidade 2012. É recorrente observar uma indefinição de classificação da área de atuação destinada a idealização e realização de espaços de curta duração. Nesta investigação pretende-se direcionar uma luz a esse assunto e será resgatada uma característica paradoxal de curta duração e ao mesmo tempo infinitude, intrínseca a origem etimológica da palavra efêmera. Propõe-se então a ressignificação da palavra e a sua habilitação para classificar arquiteturas de pouca duração que sejam inseridas em um sistema construtivo, pré e pós existente.

Com o objetivo de levantar dados precisos acerca do Pavilhão 2012, foram realizadas entrevistas semiestruturadas com a arquiteta Carla Juaçaba e o engenheiro Osmar Dutra, que atuaram sob diferentes vieses na realização do Pavilhão 2012, desde a concepção até a desmontagem. Para ancorar as propostas aqui apresentadas foi realizado amplo levantamento bibliográfico interdisciplinar abrangendo as áreas de design, arquitetura, artes visuais, geografia, antropologia e filosofia. Os autores que fornecerão a base teórica acerca da sustentabilidade no campo do design, serão: Rafael Cardoso, Ézio Manzini, John Thackara, William McDonough e Michael Braungart. A artista visual Fayga Ostrower contribuirá com a análise prática e poética de processos criativos para a materialização de ideias. A arquitetura como recurso mediador das pessoas e o mundo será trazida à tona pelo arquiteto Juhani Pallasmaa. No campo da filosofia o artigo contará com o habitar existencialista de Heidegger, a abordagem ecológica de Guattari. Como complementação da pesquisa foram também consultados artigos, matérias e vídeoentrevistas a respeito do Pavilhão Humanidade 2012, publicados a época de sua construção.

\section{Do Impermanente ao Efêmero}

Identifica-se indeterminado o entendimento e o uso da linguagem apropriada na especificação de construções de curta duração. Uma vez que tal tipo de construção constitui o foco deste artigo se torna, portanto necessário, antes de dar prosseguimento, um esclarecimento acerca da escolha de classificação do pavilhão Humanidade 2012 como uma arquitetura efêmera. No texto Construir Habitar Pensar, Heidegger dá ênfase a atenção na escolha e uso das palavras: "É salutar o cuidado com o dizer. Mas esse cuidado é em vão se a linguagem continuar apenas a nos servir como um meio de expressão" (1954/2012, p.126). Diante disso será proposto o levantamento da origem etimológica, a descrição adotada em dicionários atuais e a análise dos significados e interpretações conceituais contemporâneas das palavras: arquitetura e efêmero.

A palavra arquitetura consta no Dicionário Houaiss como: "arte e técnica de organizar espaços e criar ambientes para abrigar os diversos tipos e atividades humanas, visando também a determinada intensão plástica." (2009, p.186). Com a intenção de aprofundar o entendimento acerca da palavra arquitetura, vale recorrer a investigação da palavra arquiteto: de origem grega, a palavra arkhetekton se subdivide em arkhe - princípio, comando, força, é aquilo que existe antes de existir o mundo, a força antes da existência, e tekton - artesão, craftsman (LIDDELL;SCOTT, 1883). A articulação dessas definições nos conduz ao entendimento do arquiteto como o 
construtor de princípios, aquele que edifica o que é necessário para viver. Se faz pertinente portanto, considerar que o arquiteto tem plena condição de assumir o papel de agente capaz de estabelecer os novos princípios de construção de espaços diante dos limites do mundo. A essa exposição de significado e origem da palavra arquitetura é fundamental acrescentar o papel que a mesma vem assumindo desde o final do século XX. A arquitetura hoje é considerada muito mais do que o abrigo para atividades humanas, mas como recurso criador e potencializador de experiências. Para o arquiteto Juhani Pallasmaa a arquitetura é a mediação do ser com o mundo. Ao que ele acrescenta:

Assim como as imagens poéticas, as metáforas arquitetônicas produzem um impacto mental por meio de canais emocionais e corporalizados antes de serem compreendidas pelo intelecto; ou ainda, mesmo que não sejam compreendidas as metáforas podem nos comover profundamente. $O$ poder de uma imagem poética ou arquitetônica reside em sua habilidade de acessar sua experiência existencial diretamente, sem a manipulação ou a deliberação consciente. (PALLASMAA, 2017, p. 101-102)

É plenamente plausível classificar a princípio, o Pavilhão Humanidade 2012 como uma arquitetura impermanente, mas tal qualificação não satisfaz completamente, uma vez que a especifica somente quanto a duração de sua fruição pelo público, não abrangendo o importante significado adquirido por esta arquitetura especificamente, a partir de seu sistema construtivo. Daí a necessidade de analisar profundamente a palavra efêmero para expor o raciocínio que conduz a sua ressignificação. Efêmero é aquilo que: "1) que dura um dia [...] 3) que desabrocha e fenece no período de um dia". (HOUAISS 2009, p.723). Sobre a origem etimológica da palavra efêmero no grego, descobre-se que: "provém de uma escrita chamada Linear $B$, a forma mais antiga de grego

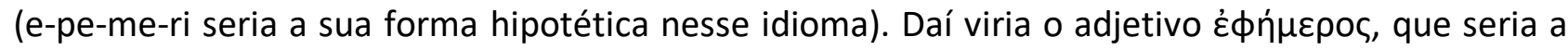
qualidade daquilo que tem vida breve, que morre e renasce no dia seguinte. Um exemplo seria a imagem da luz do sol. A palavra efêmero possui dentro dela a palavra dia (í $\mu \varepsilon ́ p \alpha$, ou heméra), o que reforça ainda mais esse caráter periódico e regular; cíclico". (LIDDELL;SCOTT, 1883). Paradoxalmente a própria palavra designa aquilo que apresenta uma curta duração, mas tende ao infinito: nasce e morre no período de um dia, porém diariamente.

As flores são um outro exemplo de efemeridade. Em geral duram pouco, algumas espécies somente um dia, mas não por isso desaparecem definitivamente. Ao longo do seu curto período de duração, são polinizadas, o que garante não só que renasçam, como também proliferem. Fica claro que a condição de efêmero não se trata daquilo que dura pouco e desaparece, mas sim daquilo que tem sua curta duração associada a uma capacidade intrínseca de continuamente ressurgir. E é justamente isso o que ocorre com a arquitetura do Pavilhão Humanidade 2012. Uma arquitetura para um uso de curta duração, que não deixa rastros, portanto impermanente, mas que ao ser inserida em um sistema pré e pós existente a sua duração, assume o valor sustentável de ressurgimento sem geração de resíduos para além da sua curta existência, o que a qualifica como uma arquitetura efêmera.

\section{O contexto e a Idealização}

Ao se deparar com o desafio da concepção de um espaço para abrigar um evento voltado para a sustentabilidade inserido na conferência global promovida pela ONU na cidade do Rio de janeiro, a diretora artística Bia Lessa teve a certeza desde o início de que a própria estrutura do pavilhão deveria comunicar o conceito de sustentabilidade e não somente se constituir como um invólucro para os assuntos que ali seriam tratados. A própria arquitetura deveria ser um acontecimento sustentável. Uma abordagem criativa alinhada com a afirmação da artista visual Fayga Ostrower: "Através da forma criada se intensifica um aspecto da realidade nova e com isso se reformula a realidade toda" (OSTROWER, 2014. p. 134-135). Ensaiando os primeiros passos 
rumo a uma construção de caráter sustentável, a primeira atitude de Lessa foi a de rejeitar o modelo construtivo básico a partir de tendas brancas climatizadas de grandes dimensões, tradicionalmente utilizado no Forte de Copacabana para grandes eventos.

Figura 1 - Vista aérea Pavilhão Humanidade

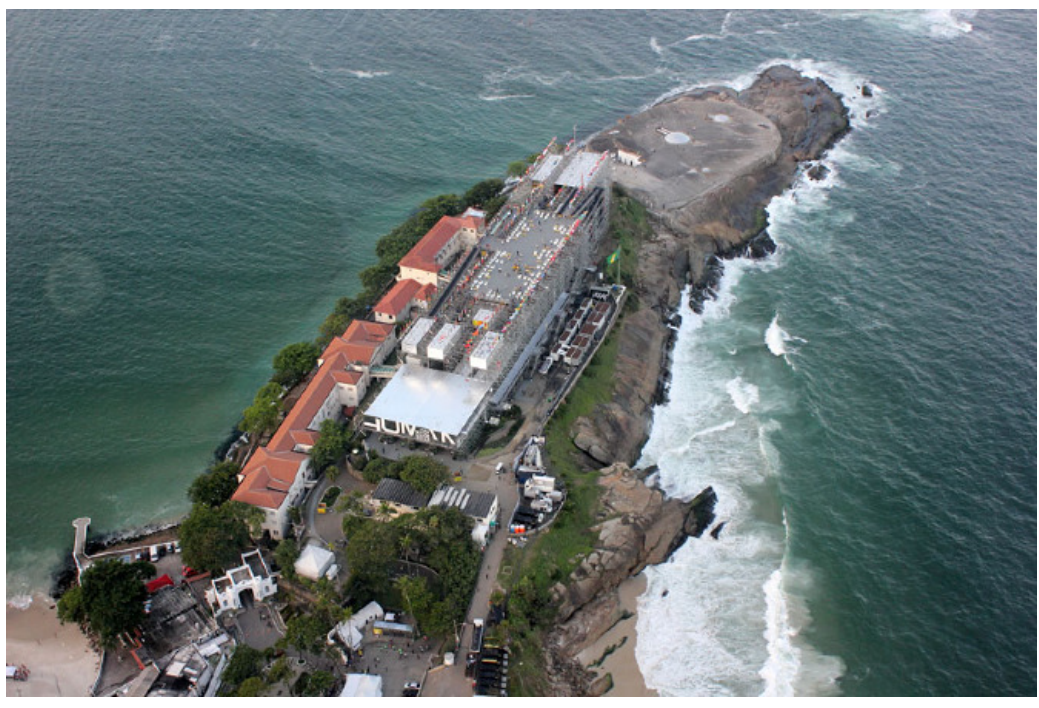

Implantação no Forte de Copacabana.

kFonte: Arquiteto Omar Muro (2012)

Já na primeira visita técnica, a arquiteta observou as estruturas de andaimes que eram utilizadas para estruturar o nivelamento do declive acentuado existente no piso da área destinada aos eventos. Foi dessa primeira percepção que surgiu a ideia da extrapolação do uso do andaime como elemento estrutural coadjuvante, para seu uso como elemento construtivo e estético principal. Surgia aí a ideia da utilização de um sistema muito familiar à área do pavilhão, não se tratando somente do Forte, mas de toda a praia de Copacabana, que recebe frequentemente tais estruturas para montagens de eventos esportivos, shows nacionais e internacionais, e em datas comemorativas.

Figura 2 - Estruturas de andaimes
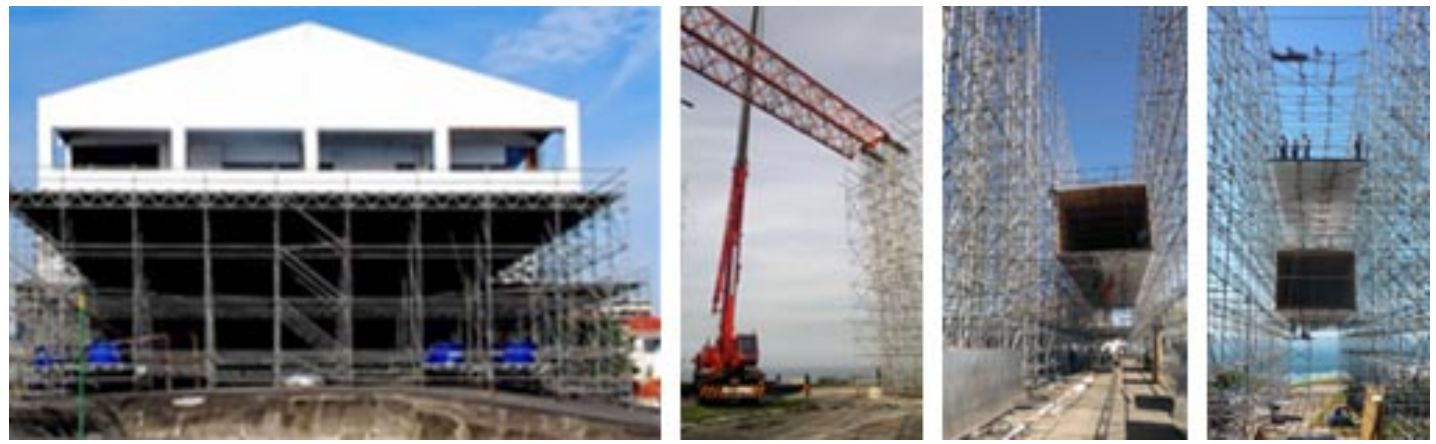

Forte de Copacabana.

Fonte: Carla Juaçaba (2011)

Como ponto de partida Lessa propôs a Juaçaba a problematização do ato de construir a arquitetura com valores de sustentabilidade, assim como problematizou a construção da informação: o conhecimento deveria ser informado através da habitação do espaço. Era preciso "in-formar" o prédio para "in-formar" o público. Era necessário provocar através da habitação do 
espaço a ser construído, a vital reaproximação das pessoas com a natureza. Essa relação atenta com a natureza deveria porém, extrapolar a experiência somente do público no espaço construído, mas afetar também a própria experiência de construção do espaço. A essa premissa acerca da natureza da experiência, proposta por Lessa, somou-se a dimensão temporal da arquitetura. Juaçaba porpôs a inserção da arquitetura impermanente em um sistema modular virtual, sem definição prévia, pré-existente e pós existente ao próprio pavilhão. $A$ impermanência se traduziu em matéria sem a geração de rastros físicos de sua existência. Dessas premissas de habitação surge a arquitetura do Pavilhão Humanidade 2012, que carrega importantes rompimentos de paradigmas e a ressignificação do construir efêmero em seu DNA. Essencialmente uma arquitetura construída a partir da expressão da sua própria subjetividade para exercer o papel de uma ponte entre o passado e o futuro, em respeito e atenção a sua impermanência no presente. Roberto Segre descreveu a atuação da arquiteta:

Não deixa de surpreender a genialidade de Carla Juaçaba, que soube transformar a sua experiência na escala residencial - os projetos de casas minimalistas, realizadas com materiais leves e industrializados - nesta complexa estrutura de andaimes de 500 toneladas totalmente desmontável, que compõe um edifício virtual. ${ }^{1}$

O convite para a participação da arquiteta Carla Juaçaba no projeto foi feito em novembro de 2011. A partir daí a aprovação inicial do projeto se deu em um mês. Nesse momento foram lançadas as bases fundamentais do projeto que se desenvolveria a partir de traços simples que definiram como estrutura principal cinco paredes autoportantes de andaimes de $170 \mathrm{~m}$ de extensão e $20 \mathrm{~m}$ de altura intertravadas por treliças metálicas. As cinco paredes principais sustentaram o circuito expositivo composto por rampas e 10 salas expositivas, além do auditório, o café cultural, a Capela e o grande terraço. O sistema construtivo previa subtrações nas estruturas para encaixes dos espaços interligados por grandes rampas de acesso, além das alternativas de circulação como os elevadores e escadas.

Os desenhos técnicos iniciais de arquitetura tiveram que ser adequados aos materiais disponíveis no mercado, uma vez que as estruturas de andaimes apresentavam modularidades variadas por serem provenientes de diferentes fornecedores devido a grande quantidade exigida pelas dimensões do projeto. Uma outra adaptação necessária se fez sentir devido a utilização das vigas de travamento e sustentação de grandes vãos. Para a composição de vãos livres de 20 metros de extensão como nos espaços do auditório e da biblioteca, que ainda sustentariam o terraço foram necessárias vigas M-150 com 2.20m de altura, comumente utilizadas na construção de pontes. Nos demais vãos de $5.40 \mathrm{~m}$ entre as cinco paredes principais foram utilizadas treliças leves de de $75 \mathrm{~cm}$ de altura. O Pavilhão Humanidade apresentou as seguintes dimensões: $170 \mathrm{~m}$ de comprimento $\times 34 \mathrm{~m}$ de largura $\times 20 \mathrm{~m}$ de altura, totalizando $5.780 \mathrm{~m}^{2}$ de área implantada e $115.600 \mathrm{~m}^{3}$ de volume construído por cerca de 1.100 toneladas de estruturas metálicas modulares.

A montagem no Forte se desenvolveu em um ritmo acelerado durante 3 meses e envolveu cerca de 200 pessoas entre as equipes de arquitetura, engenharia e cenografia. Na realidade de eventos não existe a possibilidade de haver atraso de resultados, sobretudo em um evento global como esse. Com milhares de equipes nacionais e estrangeiras envolvidas na conferência e o comprometimento das agendas de importantes chefes de estado, não podia existir qualquer atraso que implicasse um adiamento. Então dia 12 de junho o Pavilhão Humanidade 2012 estava pronto e abriu suas portas para o público.

Figura 5 - Desenhos técnicos - Cortes Longitudinais

${ }^{1}$ SEGRE, Roberto; Pavilhão Humanidade, 2012: Uma Arquitetura Frágil e Sustentável no Evento Rio+20. Revista Vitruvius. 138.02 crítica. ano 12, jun. 2012. Disponível em: http://www.vitruvius.com.br/revistas/read/projetos/12.138-139/4403. Acesso em: 15 de mai. 2018. 


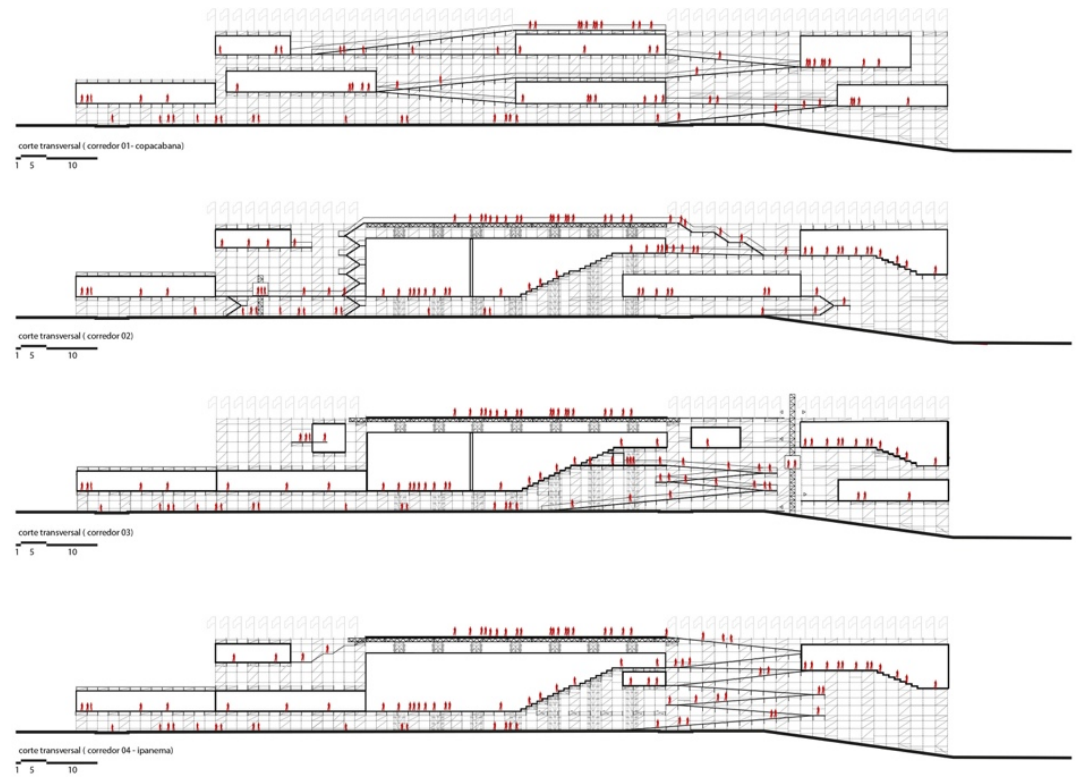

Pavilhão Humanidade 2012.

Fonte: Carla Juaçaba (2012)

A montagem no Forte se desenvolveu em um ritmo acelerado durante 3 meses e envolveu cerca de 200 pessoas entre as equipes de arquitetura, engenharia e cenografia. Na realidade de eventos não existe a possibilidade de haver atraso de resultados, sobretudo em um evento global como esse. Com milhares de equipes nacionais e estrangeiras envolvidas na conferência e o comprometimento das agendas de importantes chefes de estado, não podia existir qualquer atraso que implicasse um adiamento. Então dia 12 de junho o Pavilhão Humanidade 2012 estava pronto e abriu suas portas para o público.

... Foi um trabalho a fórceps,[...] um esforço coletivo gigantesco mas ao mesmo tempo é muito parecido com a situação que a gente está vivendo atualmente, quer dizer, é importante que o homem dê um passo pra frente a fórceps,... o planeta vem dizendo que a forma que a gente está lidando não só com ele, mas com a gente mesmo [...] está num limite [...] então eh fundamental que a gente descubra uma nova forma de viver e essa nova forma de viver tem urgência [...]perceber a urgência com que ele foi feito, também faz parte desse conteúdo da urgência de uma necessidade de transformação do indivíduo em todas as esferas, governamental, individual...2

Tabela 1 - Quantitativos das estruturas modulares.

\begin{tabular}{|l|l|l|l|l|l|l|}
\hline $\begin{array}{l}\text { Elementos } \\
\text { estruturais } \\
\text { modulares }\end{array}$ & $\begin{array}{l}\text { Estrutura tubular } \\
\text { sistema de encaixe } \\
\text { e tubo e braçadeira }\end{array}$ & $\begin{array}{l}\text { Treliças } \\
\text { leves }\end{array}$ & $\begin{array}{l}\text { Vigas } \\
\text { M-150 }\end{array}$ & $\begin{array}{l}\text { Vigas metálicas 3" x } \\
\text { 3" para estrutura dos } \\
\text { pisos }\end{array}$ & $\begin{array}{l}\text { Mills } \\
\text { tour }\end{array}$ & totais \\
\hline $\begin{array}{l}\text { Metragem } \\
\text { linear }\end{array}$ & 170.000 & 11.000 & 400 & 5.000 & 15.000 & 101.400 \\
\hline $\begin{array}{l}\text { Peso em } \\
\text { toneladas }\end{array}$ & 765 & 110 & 80 & 25 & 120 & 1.100 \\
\hline
\end{tabular}

Fonte: Engenheiro Osmar Dutra

Uma característica importante que a arquiteta destaca em relação a essa experiência construtiva, é o fato dela ser completamente autoportante, o que se adequou muito bem às

${ }^{2}$ LESSA, Bia em entrevista concedida ao canal de youtube - https://www.youtube.com/watch?v=Azndo2_wVjg 
condições existentes, lembrando que foram 7.000 pontos de apoio sem nenhum tipo de atirantamento ou de fixação na rocha. Juaçaba afirma que "apesar do grande porte apresentado, foi a solução menos agressiva que pode existir uma vez que ao ser retirada deixou o solo intacto."3

\section{As Dimensões de Sustentabilidade}

O imperativo econômico no projeto se constituiu como um paradoxo: Se por um lado o investimento foi gigantesco na realização do pavilhão, por outro lado representou forte obstáculo à concretização de um planejamento sustentável de ponta a ponta. Sem tempo hábil, as metas de sustentabilidade se restringiram à seleção dos materiais e dos sistemas de construção.

São altos os custos para a implantação de novos parâmetros de trabalho, ocasionados e agravados pela generalizada falta de informação e orientações sustentáveis nessa área, além da resistência da mão de obra disponível, uníssonas à resistência do próprio cliente investidor.

Não haverá verdadeira resposta à crise ecológica a não ser em escala planetária e com a
condição de que se opere uma autêntica revolução política, social e cultural reorientando
os objetivos da produção de bens materiais e imateriais. Essa revolução deverá concernir,
portanto, não só às relações de forças visíveis em grande escala, mas também aos
domínios moleculares de sensibilidade, de inteligência e de desejo. (GUATARRI, 2012, p.9)

Quando se menciona o estabelecimento de novos parâmetros sustentáveis de trabalho na materialização de uma arquitetura impermanente, como o Pavilhão Humanidade 2012, a lista é extensa e abrange parâmetros de pelo menos três dimensões de sustentabilidade, a ambiental, a cultural e a social.

Na dimensão ambiental foi mencionada a palavra otimização, o que torna importante esclarecer que otimizar ainda é uma abordagem inicial na busca de soluções sustentáveis rumo a real necessidade de tolerância zero em relação aos parâmetros estabelecidos anteriormente. Na dimensão ambiental, a escolha do método construtivo de arquitetura efêmera, ou seja de curta duração inserida em um sistema pré e pós existente, foi determinante para a diminuição do impacto ambiental da construção resultante da diminuição da geração de resíduos, além da otimização de energia e de emissão de gases poluentes no transporte de materiais.

Na dimensão cultural, o projeto se destaca como eficiente instrumento de transmissão de informação através dos mais variados recursos, desde a informação direta até a informação simbólica conceitual através de uma arquitetura extremamente significativa, como foi abordado no item anterior em que foi descrita a experiência do público e das equipes de realização.

Na dimensão social a prioridade se manteve em oferecer ao público uma habitação do espaço significativa e experimental de aproximação da natureza, além de condições de bem-estar durante a visitação. Porém o mesmo não ocorreu durante o trabalho de detalhamento técnico, construção e montagem. Devido ao reduzido período de tempo para a realização do projeto, o que é uma prática bastante comum na realização de arquiteturas impermanentes nas diversas áreas voltadas para eventos. No país não há uma regulamentação estabelecida para as atividades técnicas e artísticas nesse campo, o que favorece a sistemática execução dessas atividades em prazos sempre subdimensionados o que evidentemente força as equipes a trabalharem por jornadas muito mais longas do que as previstas 8 horas diárias de trabalho.

Para analisar os resultados alcançados de otimização de geração de resíduos materiais na dimensão da sustentabilidade ambiental, é fundamental que a arquitetura do pavilhão seja separada da cenografia das salas expositivas. A escolha de boa parte do material utilizado na

${ }^{3}$ Entrevista JUAÇABA, Carla. Arquiteta. Entrevista concedida a autora em: 18 de jul. 2017. 
cenografia teve como foco placas de OSB, MDF e tetrapac. De certa forma, criou-se assim um ponto de familiaridade importante para tornar mais palatável a absorção do significado daquele lugar e das ideias de sustentabilidade transmitidas, uma vez que esse materiais são as opções mais populares e disponíveis para a composição de um discurso retórico visual. É importante frisar que tais materiais constituem somente uma representação de sustentabilidade, uma vez que os processos de reciclagem de materiais não são efetivamente sustentáveis. Nesses processos ocorrem gastos de energia, emissão de gases poluentes que resultam em geral em compostos de difícil dispersão e reabsorção na natureza. As etapas do processo completo de concepção e realização de uma arquitetura impermanente podem ser expostas de acordo com a cadeia criativa-produtiva tradicional e mais praticado na atualidade:

Figura 9 - Evolução de articulações na cadeias criativa-produtiva
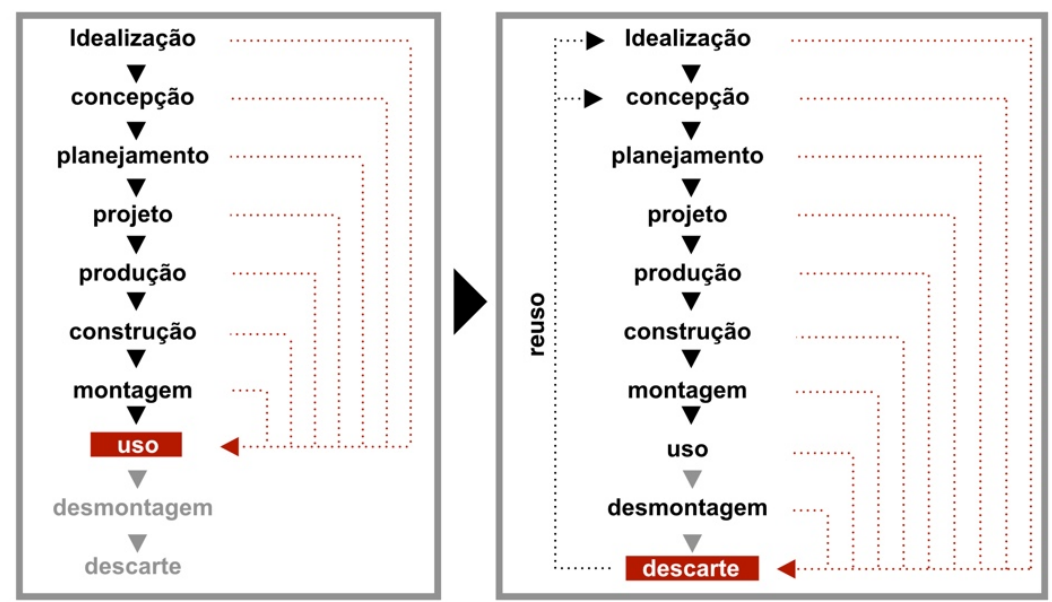

Duas possibilidades de articulação das etapas

Fonte: Elaboração própria (2018)

Na cadeia criativa-produtiva acima a esquerda, nota-se a prioridade absoluta da etapa de uso do espaço. Todas as etapas desde a idealização até a montagem visam somente o momento do uso e desconsidera as duas últimas etapas relativas a desmontagem e descarte dos materiais. 0 sucesso da realização de uma arquitetura impermanente é restrito a eficiência do seu funcionamento, o resultado de sua construção, o acabamento dos detalhes e a concepção estética que apresenta. Isso leva a uma profunda subutilização dos materiais, uma vez que são comumente utilizados, beneficiados e misturados materiais duráveis na composição das construções de curta duração.

Em contrapartida à concepção cenográfica, a concepção arquitetônica não se restringiu a um discurso retórico a respeito da sustentabilidade. A concepção arquitetônica experimentada na concepção do pavilhão não somente forneceu expressiva visibilidade ao debate acerca de construções sustentáveis de curta duração, como propôs eficientemente a articulação de aspectos projetuais rumo a redução do impacto ambiental e a mudança na percepção de bem-esta. No processo de realização, a partir da escolha de um sistema construtivo modular existente para a construção do pavilhão, logo de início se destaca a direta alteração no tradicional fluxograma do processo de realização de arquiteturas impermanentes:

Na cadeia criativa-produtiva acima a direita, todas as atividades previstas já consideram o descarte como fator norteador de suas tomadas de decisão. O tipo de descarte a ser determinado vai influenciar desde a idealização e concepção criativa até as diretrizes de produção, a montagem 
e também a desmontagem. Para que uma realização se torne efetivamente sustentável, não basta somente restringir esse conceito a estética, ao sistema construtivo e a escolha dos materiais. Metas de redução do impacto ambiental tem que estar presentes em todas as etapas do processo, principalmente nas etapas de idealização, concepção e planejamento.

$\mathrm{Na}$ construção de arquiteturas impermanentes tradicionais, em geral nada ou somente uma pequena porcentagem do material pode ser reutilizado e mesmo assim terá sua aplicação limitada e um prazo curto de reutilização. Na construção da arquitetura do pavilhão Humanidade 2012 o resultado é impactante: foram $115.600 \mathrm{~m}^{3}$ construídos em sistemas modulares de andaimes e de sua desmontagem resultaram $115.600 \mathrm{~m}^{3}$ de estruturas modulares de andaimes plenamente aptos ao reuso em novas construções efêmeras.

\section{Considerações Finais}

Neste momento de transição em que é fundamental o estreitamento da relação serhumano-natureza, rumo a diminuição do impacto ambiental, evidencia-se que a maior preocupação da humanidade não deve ser com aquilo que efetivamente dura pouco, mas sim com aquilo que dura muito. O grande problema dos espaços impermanentes ou temporários não é a sua curta duração, mas sim a durabilidade dos materiais utilizados. Por isso torna-se necessário enfatizar a importância da transformação de arquiteturas impermanentes em arquiteturas efêmeras a partir da inserção de sua construção em sistemas que permitam o reuso integral dos materiais utilizados, diminuindo consideravelmente a geração de resíduos e consequentemente o impacto no meio ambiente na realização de tais construções. Para tanto, identifica-se a necessidade de um incremento sensível no ensino, pesquisa e desenvolvimento de sistemas construtivos leves e modulares que possam ser criativamente associados ao prazer estético e a valores sustentáveis.

Fica claro que Pavilhão Humanidade 2012 não foi um projeto que assumiu um compromisso de tolerância zero no impacto ambiental em sua realização. Todas as decisões de projeto e de realização tiveram dois objetivos norteadores: Por em prática de fato, apesar de todas as condições desfavoráveis, uma construção com algum valor real de sustentabilidade, e constituir um grito potente de alerta. Por condições desfavoráveis, entende-se a falta de referências prévias e portanto, a falta de parâmetros nessa área, assim como a falta de conhecimento disponível e o recorrente sub-dimensionamento do tempo. Tempo é um recurso do qual não dispomos em abundância visto o limite em que se encontra o planeta, mas seu dimensionamento correto na materialização de ideias é um aliado fundamental rumo a diminuição do impacto ambiental. O tempo atua como um recurso imaterial imprescindível para qualquer realização humana, principalmente para a realização de arquiteturas efêmeras pois ainda há muito o que ser pesquisado para um real avanço nessa área. E isso só será possível a partir de consistentes pesquisas e planejamentos de todas as etapas do processo, desde a concepção até a desmontagem e descarte dos materiais utilizados.

A partir da análise do pavilhão humanidade 2012 como um protótipo de solução rumo a um rompimento sistêmico na realização de arquiteturas para curtos períodos de uso, surgiu inclusive a oportunidade de ressignificar a palavra efêmero para qualificar tais construções, e ratificar seu caráter sustentável. Para Ézio Manzini, um protótipo de solução significa que "uma ideia de serviço é viável e que alguém em algum lugar, foi capaz de colocá-la em prática." (2008, p.79). A escolha da construção do pavilhão em sistema de andaimes foi o grande acerto do projeto rumo a diminuição ambiental. Foi um importante primeiro passo de grande dimensão nesse 
momento de transição em que é necessário experimentar novas maneiras de lidar com os materiais, com o consumo de energia e emissão de gases poluentes.

Investigar e divulgar a experimentação realizada no pavilhão Humanidade 2012 permite a ampliação para o campo teórico das conquistas práticas do projeto e se afirma como mais um meio para que tal iniciativa abra cada vez mais possibilidades práticas em contextos diversos. A mudança rumo à diminuição do impacto ambiental virá do conhecimento, da compreensão e definição de possibilidades que, por sua vez acarretarão mudanças morais, práticas e éticas. 0 pavilhão Humanidade 2012, pode ser considerado como uma iniciativa de resposta a pergunta provocadora e inspiradora de McDonough: "E se as sociedades modernas fossem vistas como ampliadoras de bens e de deleites em escala realmente grande, em vez de levarem o planeta a beira do desastre?" (2002 p.92). Mais do que uma pergunta, essa frase soa como um convite para repensar e agir diferente. Instigada a contribuir, nesse momento escolho compartilhar conhecimento.

\section{Referências}

CARDOSO, Rafael. Design Para um Mundo Complexo. São Paulo: Ed. UBU, 2016. 262p.

GAUSA, Manuel; GUALLART, Vicente; MULLER, Willy; SORIANO, federico; PORRAS, Fernando;

MORALES, José; coord. CROS, Susanna. The Metapolis Dictionary of advanced Architecture: City, Technology and society in the information age. Barcelona: Actar, 2003. 688p.

GUATTARI, Félix. As Três Ecologias. Campinas, SP: Papirus 21a ed. 5a reimpressão 2012. 56p.

HEIDDEGER, Martin. Construir Habitar Pensar, in: Ensaios e Conferências. Petrópolis: Vozes, 2002. $269 p$.

HOUAISS, Antônio; VILLAR, Maurio de Salles. Dicionário Houaiss da Língua Portuguesa. Rio de Janeiro: Objetiva, 2009. 1986p.

LIDDELL, Henry George, and SCOTT, Robert, eds. Intermediate Greek-English Lexicon. Reino Unido: Oxford University Press, 1883.

MANZINI, Ezio. Design para Inovação Social e Sustentabilidade: Comunidades Criativas, Organizações Colaborativas e Novas Redes Projetuais. Rio de Janeiro: E-papers, 2008. 104p.

MC DONOUGH, William; BRAUNGART, Michael. Cradle to Cradle: Remaking the way to make things. California: North Point Press, 2002. 208p.

OSTROWER, Fayga. Criatividade e Processos de criação. Petrópolis: Vozes, 2014. 186p.

PALLASMAA, Juhani. Habitar. São Paulo: Gustavo Gili, 2017. 125p.

SEGRE, Roberto; Pavilhão Humanidade, 2012: Uma Arquitetura Frágil e Sustentável no Evento Rio+20. Revista Vitruvius. 138.02 crítica. ano 12, jun. 2012. Disponível em:

http://www.vitruvius.com.br/revistas/read/projetos/12.138-139/4403. Acesso em: 15 de mai. 2018.

THACKARA, John. Plano B: O Design e as Alternativas Viáveis em um Mundo Complexo. São Paulo: Saraiva, 2008. 299p. 